\title{
Carnets
}

Revue électronique d'études françaises de l'APEF

Première Série - 5 | 2013

Métamorphoses littéraires

\section{Éditorial : Métamorphoses littéraires}

\section{(2) OpenEdition \\ 1 Journals}

Édition électronique

URL : http://journals.openedition.org/carnets/8107

DOI : 10.4000/carnets.8107

ISSN : 1646-7698

Éditeur

APEF

Édition imprimée

Date de publication : 1 mai 2013

Pagination : 5-7

Référence électronique

"Éditorial : Métamorphoses littéraires », Carnets [En ligne], Première Série - 5 | 2013, mis en ligne le 23 juin 2018, consulté le 24 septembre 2020. URL : http://journals.openedition.org/carnets/8107 ; DOI : https://doi.org/10.4000/carnets.8107

\section{(c) (7) (9)}

Carnets est mis à disposition selon les termes de la licence Creative Commons - Atribution - Pas d'utilisation commerciale 4.0 International. 


\section{Carnets}

http://carnets.web.ua.pt

\section{Éditorial Carnets V}

\section{Métamorphoses littéraires}

Inauguré dans la culture occidentale par le texte fondateur des Métamorphoses d'Ovide (ce long poème épique qui récupère des légendes héritées de la tradition grecque et latine jusqu'au temps d'Auguste), le thème de la métamorphose connaît d'innombrables formulations et transformations au long de l'histoire des littératures. C'est ainsi que - la diversité des études présentées dans ce numéro de Carnets en témoigne - ce thème hérite d'un vaste imaginaire culturel, dont les images circulent du profane au sacré (et Laurent Pietra s'est proposé d'interpréter les métamorphoses de la figure de Joseph dans quelques textes de la littérature religieuse chrétienne), tout autant qu'il le stimule. Un imaginaire souvent à la frontière du discours oral et du récit, qui récupère, entre combien d'autres légendes dont les origines se perdent dans le temps, celles du loup-garou (figure qui intéresse Loren Gonzalez, en tant que véhicule privilégié du passage du paganisme au christianisme opéré par la littérature médiévale), ou fait défiler devant les yeux du lecteur des personnages qui traversent la tradition littéraire comme Narcisse (dont quelques métamorphoses sont étudiées par Alina-Daniela Marinescu, à la lumière des figures de la "mise en abîme, de la parodie et de l'intertextualité" dans trois textes de Guillaume de Lorris, Jean de Meun et Evrart de Conty), ou des auteurs dont les possibilités d'actualisation nous frappent, comme Chrétien de Troyes, dont Sylvia Roustant étudie "la continuité et la rupture avec le modèle ovidien" qui fonde son œuvre, ou Claude Crébillon (dont Ana Alexandre Carvalho lit les quatre récits, Le Sylphe, L'Écumoire, Le Sopha e Ah Quel Conte!).

En mettant l'accent sur la surface des choses ou sur leur essence ontologique, le processus de la métamorphose se révèle une constante dans la formation (et la formulation) des univers fictionnels. La quête de repères historiques et philosophiques aux divers processus de métamorphoses qui accompagnent l'histoire des littératures s'est ainsi révélée la source d'un travail inépuisable depuis les littératures de l'Antiquité jusqu'aux littératures contemporaines, la théorie et la critique littéraires suivant de près ces évolutions, qui intéressent autrement le domaine des études comparées.

La métamorphose conjure ainsi l'être au monde des écrivains tout autant que celui des lecteurs, dans une invitation permanente aux ressources de leur imagination créatrice. Le processus de dé-figuration et de re-figuration dynamique et ininterrompu auquel elle invite fait appel à de nouvelles formes d'expression et se constitue en domaine de recherches 
linguistiques, sociologiques et anthropologiques tout aussi intéressants. Un processus qui acquiert des connotations très particulières dans le domaine littéraire lorsque les poètes s'invitent à lire d'autres poètes. C'est justement sur Gérard de Nerval, lecteur de poètes du XVle siècle, et à propos de sa contribution au mouvement romantique en tant qu'auteur de l'anthologie Choix des poésies de Ronsard, Du Bellay, Baïf, Belleau, Du Bartas, Chassignet, Desportes, Régnier que s'interroge Marta Kawano, à partir de la réédition de l'œuvre complète du poète dirigée par Jean-Nicolas Illouz, inaugurée en 2011 aux éditions Garnier. Un processus d'interrogation sur le monde au cœur duquel Nerval et ses contemporains ont finalement élit domicile, à leur manière d'être poètes, que Beryl Schlossman choisit d'étudier, à son tour, par le biais des figures du poète, allégories du "Cygne" et des métamorphoses jamais accomplies du "paysage urbain" dans l'œuvre de Baudelaire, dont elle est spécialiste.

Considérée par quelques-uns comme postmoderne (à la suite des propositions de Jean-François Lyotard, dont Georges Van Den Abeelle étudie l'évolution de l'œuvre), la production littéraire de la seconde moitié du XXe siècle et contemporaine valorise des dénominateurs communs tels que la métafiction, la réécriture et l'intertextualité. Ces processus littéraires signalent implicitement et explicitement la transformation des discours et des genres préexistants (et, pour Cristina Álvares, la microfiction résulte des processus de métamorphose subis par le conte dans le livre Petits Chaperons, de José Luis Zárate) tout autant qu'ils engagent une constellation de thèmes de nature diverse: certains s'inscrivent dans la tradition littéraire, d'autres révèlent des aspects culturels d'ascendance historique et sociale.

Notre époque cultive les états éphémères, les changements subits et imprévisibles: la turbulence et l'incertitude qui la caractérisent nourrissent la culture de la métamorphose qui définit la contemporanéité. L'espace transfrontalier où s'écrivent, de nos jours, les littératures en français accentue la nature fluide des objets poétiques. L'étude de Zsuzsa Simonffy l'illustre pour le cas des écrivains Maurice Carême et Marcel Thiry, dont l'œuvre institue la métamorphose au cœur du fantastique, prenant le risque de créer des ambiances déshumanisantes.

Ainsi, la conscience de l'évolution littéraire, surtout à partir de la deuxième moitié du XXe siècle, et jusqu'à nos jours, s'est souvent manifestée, non pas tant comme une évolution linéaire et progressive, mais plutôt comme une évolution cyclique du retour et de la réinscription de processus littéraires déjà connus, qu'elle n' hésite pas à revisiter pour les désacraliser. La "retractatio du récit ovidien" est à l'œuvre dans l'analyse de quelques poèmes du contemporain Jean Ristat, dont Artémis chasse à courre le sanglier, le cerf et le loup, présentée par Linda Maria Baros.

Toujours révélatrice du rapport de l'homme au réel, et de son engagement au monde, la métamorphose médiatise ce rapport en faisant usage de diverses pratiques discursives. 
Le recours à la caricature en est une formulation, particulièrement cruelle, sinon féroce, mais singulièrement abondante lors de moments politiques aigus. L'histoire des rapports politiques entre la France et l'Angleterre, dont la richesse a inspiré bien des témoignages, a poussé I'historien Reto Monico à tout un travail d'exégèse de la revue L'Assiette au beurre, où il a puisé des illustrations uniques, qui ne manqueront pas de surprendre les lecteurs de Carnets, à la clôture de ce numéro.

\section{Remerciements}

La direction de Carnets adresse à I'historien Reto Monico sa vive reconnaissance envers son aimable collaboration à ce numéro.

La collaboration de l'étudiante de la licence en Línguas, Literaturas e Culturas (filière Langues et Tourisme) de l'université d'Évora, Maryline Falcato, à ce numéro, pour lequel elle a composé l'illustration de la couverture, de même que celle de l'étudiant du II cycle en Études de l'édition de l'université d'Aveiro, Bruno Martins, responsable de sa composition et de sa mise en pages, témoigne du travail en équipe qui a réuni les éditeurs de ce numéro. Travail d'équipes renouvelées à chaque nouveau numéro, qui définit l'espace où se développe le projet éditorial de Carnets (revue en ligne de l'Association portugaise en études françaises), appuyé par la disponibilité de notre Secrétaire, Corina Soares, docteur en Littérature française, et par l'équipe des Services de Biblioteca, Informação Documental e Museologia de l'Université d'Aveiro, qui l'héberge dans sa plateforme de revues numériques, à l'abri de DOAJ.

À tous, l'expression de notre gratitude Carnets.

La direction de Carnets 